\title{
Chemical constituents in volatile oil of rhizome and flower of Curcuma angustifolia Roxb. growing in North-East India
}

\author{
Naoroibam Shilpia Devi, Ningthoujam Sandhyarani Devi` and R. K. Imotomba Singh
}

Department of Agricultural Biotechnology, Pandit Deen Dayal Upadhyay Institute of Agricultural Sciences, Bishnupur-795134, Manipur, India

\section{Article Info}

Article history

Received 7 October 2021

Revised 26 November 2021

Accepted 27 November 2021

Published Online 30 December 2021

\section{Keywords}

Curcuma angustifolia Roxb.

GC-MS analysis

Volatile oil

Zingiberaceae

\begin{abstract}
Curcuma angustifolia Roxb. (Family: Zingiberaceae) is an important rhizomatous medicinal and aromatic plant. The rhizome and flower essential oil of $C$. angustifolia were extracted using methanol and analyzed by Gas chromatography/mass spectrophotometry (GC-MS). The oil yield (\% v/w) of the rhizome and flower were 3.25 and 2.40 , respectively. A total of 24 and 42 compounds were identified, representing 77 $91 \%$ and $46-61 \%$ of the total rhizome and flower oil, respectively. The major constituents in the rhizome oil were germacrone $(27.52 \%), \beta$-pinene $(16.46 \%)$ and $\beta$-elemene $(15.32 \%)$ followed by $\beta$-elemenone $(8.42 \%)$ and germacrene $(5.68 \%)$. The major constituents in the flower oil were $\beta$-germacrene $(22.44 \%)$, 2,2,7,7-tetramethyl tricycle [6.2.1.0](1,6)] undeca-4-en-3-one (15.63\%), caryophyllene oxide $(7.12 \%)$, followed by $\beta$-caryophyllene $(6.84 \%)$ and methyl isomyristate $(5.23 \%)$. Because of the presence of remarkable phytoconstituents, the rhizome and flower essential oil of $C$. angustifolia would have enough significance in the preparation of pharmaceutical drugs.
\end{abstract}

\section{Introduction}

Curcuma angustifolia Roxb. belonging to the family Zingiberaceae, is an important aromatic and medicinal herb (Srivastava et al., 2006). Though, distribution of Zingiberaceae is worldwide with over 100150 species, they are predominantly concentrated in Thailand, China and the Indian Sub-continent (Wu and Larsen, 2000; Triboun, 2006). Many members of Zingiberaceae are of outstanding importance economically since their volatile oils form indispensable ingrediens of perfumery, flavour, fragrance and pharmaceutical industries. The family is of great ethnobotanical value being employed in many indigenous medical systems. Many members of Zingiberaceae are employed in Ayurvedic, Unani, and Homoeopathic systems of medicine.

C. angustifolia is distributed throughout central, southern and eastern India, but most commonly reported from the Northeast and Western Coastal Plains and hills of India (Srivastava et al., 2006; Sharma, 2012). People called C. angustifolia in different names, viz., East Indian Arrowroot in English, tikhur in Hindi, yaipan in Manipuri and Koova in Malayalam. Rhizomes of $C$. angustifolia have been used in ethnomedicine in India as an antiasthmatic, antidysentry, antifungal and anmtipyretic (Tushar et al., 2010; Ray et al., 2011; Padal and Sandhyasri, 2013). Rhizomes are used for the treatment of bone fracture, inflammation and intestinal disorders (Jain, 1995). C. angustifolia produces beautiful flowers and foliages that have commercial value in floriculture as ornamental crops (Maciel and Criley, 2003). Various parts of this plant species have been used

Corresponding author: Dr. Ningthoujam Sandhyarani Devi Assistant Professor, Department of Agricultural Biotechnology, Pandit Deen Dayal Upadhyay Institute of Agricultural Sciences, Bishnupur795134, Manipur, India

E-mail: sandhyarani.nin@gmail.com

Tel.: +91-9774684044

Copyright (c) 2021 Ukaaz Publications. All rights reserved.

Email: ukaaz@yahoo.com; Website: www.ukaazpublications.com either raw or cooked as vegetables in many Asian countries (Devi et al., 2014). This plant grows wild in various locations of North East India and the localities of Manipur, Nagaland, Meghalaya and Mizoram consume the inflorescence as food. Local community of Manipur use the flower as a delicacy in various dishes because of its distinct intriguing taste and is popularly used in a chutney known as Eromba. Plants used in traditional medicine are still a large source of natural antioxidant, antimicrobial, anticancer agents that might lead to the development of novel drugs (Lee et al., 2004) and many naturally occurring substances present in the human diet have been identified as potential chemo-preventive agents against cancer (Atlas et al., 1995). Many plants are being utilized as medicines by humans to fight against various diseases since their inception on this Earth (Alam et al., 2019). Natural antioxidant effects of compounds derived from medicinal plants are most popular nowadays (Manoharachary and Nagaraju, 2016).

Rhizomes of $C$. angustifolia have been reported by some investigators as rich sources of volatile oils which give them pleasant aroma and medicinal value (Srivastava et al., 2006; Sudipta et at., 2017). However, the volatile oil composition of flower of $C$. angustifolia has not been reported so far. This prompted us to carry out detailed GC and GC-MS examination of rhizome and flower oils of $C$. angustifolia from North East India.

\section{Materials and Methods}

\subsection{Plant materials}

Rhizomes and flowers of $C$. angustifolia were collected (Figures 1; a, b) from Bishnupur district, Manipur, North East India (25 $50^{\circ}$ $24^{\circ} 43 \mathrm{~N} ; 92^{\circ} 58^{\prime}-94^{\circ} 45^{\prime} \mathrm{E}$ ) in November 2020 . The plants were identified by taxonomist and voucher specimens (Accession No. PDDUIAS-CA101) were deposited at the Herbarium of Department of Agricultural Biotechnology, Pandit Deen Dayal Upadhyay Institute of Agricultural Sciences, Manipur. 


\subsection{Extraction of essential oil}

The fresh rhizomes $(750 \mathrm{~g})$ and flowers $(500 \mathrm{~g})$ were harvested and washed under running tap water separately and then subjected to distillation for $5 \mathrm{~h}$ in a Clevenger type apparatus (Guether, 1972) in methanol. The essential oils were dried over anhydrous sodium sulphate and stored in air tight eppendorf tube at $4^{\circ} \mathrm{C}$ for further investigation.

\subsection{Gas chromatography/mass spectrometry analysis}

GC-MS analysis was performed on a Clarus $680 \mathrm{GC}$ with Clarus 600 C mass spectrometer system, Perkin Elmer, USA with Liquid Auto Sampler, Column $60.0 \mathrm{~m}$ long, $250 \mu \mathrm{m}$ coating thickness. The GC was operated under the following conditions: Initial temperature $60^{\circ} \mathrm{C}$ for $2 \mathrm{~min}$, ramp $4^{\circ} \mathrm{C} / \mathrm{min}$ to $200^{\circ} \mathrm{C}$, hold $5 \mathrm{~min}$, ramp $8^{\circ} \mathrm{C} / \mathrm{min}$ to $260^{\circ} \mathrm{C}$, sample volume $2 \mu 1$, split 0:1; Solvent delay $=10.00 \mathrm{~min}$, Transfer temp $=200^{\circ} \mathrm{C}$, Scan : 40 to $400 \mathrm{Da} .2 \mu \mathrm{l}$ volume of ethyl acetate extract was injected into the GC. Carrier gas was helium $(99.99 \%$ purity) at a constant flow rate of $1.0 \mathrm{ml} / \mathrm{min}$. Mass spectrometer was operated in full scan with $70 \mathrm{eV}$.

\subsection{Identification of compounds}

Identification of compounds was done by means of their retention time and final confirmations of compounds were done by matching their mass spectra (MS) with NIST 2005 Library data and literature. Quantitative analysis was done on the basis of its peak area measurement from the TIC without response factors.

\section{Results}

\subsection{Rhizome volatile oils}

The composition of the rhizome volatile oil has been investigated by combination of GC and GC-MS analysis. The volatile oils were obtained by conventional hydrodistillation technique. The oil yield was 3.25\% (v/w). GC-MS identified a total of 24 compounds from the rhizome representing $77-91 \%$ of the total rhizome oils (Table 1; Figure 2, a). The major constituents in the rhizome oils of $C$. angustifolia were germacrone $(27.52 \%)$, $\alpha$-pinene $(16.46 \%)$, $\alpha$-elemene $(15.32 \%), \alpha$ elemenone $(8.42 \%)$, germacrene $(5.68 \%)$ and caryophyllene $(2.49 \%)$. The percentage composition of other trace constituents in the rhizome oils did not show much difference, as evident from Table 1.

Table 1: Volatile oil composition of rhizome and flower of $C$. angustifolia from North East India

\begin{tabular}{|c|c|c|c|c|}
\hline Peak & Name of compound ${ }^{a}$ & RT & Rhizome oil (\%) & Flower oil $(\%)$ \\
\hline 1. & $\beta$-pinene & 12.925 & 16.460 & $\operatorname{tr}$ \\
\hline 2. & $\beta$-phellandrene & 12.870 & $\operatorname{tr}$ & $\operatorname{tr}$ \\
\hline 3. & Eucalyptol & 15.191 & - & 0.121 \\
\hline 4. & Camphore & 20.323 & $\operatorname{tr}$ & 15.635 \\
\hline 5. & $\alpha$-bergamotene & 25.080 & $\operatorname{tr}$ & $\operatorname{tr}$ \\
\hline 6. & $\beta$-germacrene & 25.135 & 5.681 & 22.442 \\
\hline 7. & Acoradien & 25.165 & - & $\operatorname{tr}$ \\
\hline 8. & Cis-chrysanthemol & 25.200 & $\operatorname{tr}$ & $\operatorname{tr}$ \\
\hline 9. & Trimethyl- 1,5,9- cyclododecatriene & 25.595 & 0.267 & - \\
\hline 10. & $\beta$-elemene & 25.780 & 1.301 & - \\
\hline 11. & $\beta$-caryophyllene & 26.336 & 2.486 & 6.844 \\
\hline 12. & Ò-elemene & 26.426 & 15.321 & 0.257 \\
\hline 13. & $\beta$-farnesene & 26.571 & - & $\mathrm{tr}$ \\
\hline 14. & $\alpha$-caryophyllene & 27.406 & 2.486 & 0.456 \\
\hline 15. & Germacrene D & 28.116 & $\operatorname{tr}$ & 0.674 \\
\hline 16. & $\alpha$-farnesene & 28.172 & $\mathrm{tr}$ & $\operatorname{tr}$ \\
\hline 17. & $\alpha$-funebrene & 28.446 & - & 0.367 \\
\hline 18. & Hexadeca- 1,11 diyne & 28.827 & 0.023 & - \\
\hline 19. & Isocericenin & 29.077 & - & 0.782 \\
\hline 20. & Curzerene & 29.102 & 0.680 & $\operatorname{tr}$ \\
\hline 21. & Petasitene & 29.972 & - & $\operatorname{tr}$ \\
\hline 22. & Caryophyllene oxide & 31.753 & $\mathrm{tr}$ & 7.120 \\
\hline 23. & $\beta$-elemenone & 32.373 & 8.423 & 0.403 \\
\hline 24. & Germacrone & 32.393 & 27.519 & 4.034 \\
\hline 25. & Methenolone & 33.394 & $\operatorname{tr}$ & $\mathrm{tr}$ \\
\hline
\end{tabular}




\begin{tabular}{|c|c|c|c|c|}
\hline 26. & Bicyclo (3.3.0) oct-1-en-3-one & 33.598 & - & 0.391 \\
\hline 27. & Phenol 4-(( dimethylamino) sulfony) methylamino & 34.409 & 0.076 & - \\
\hline 28. & 2- norbornanone & 34.489 & 1.233 & - \\
\hline 29. & Methyl isotridecanoate & 38.035 & - & 0.724 \\
\hline 30 . & Methyl isomyristate & 38.070 & $\operatorname{tr}$ & 5.230 \\
\hline 31. & Methyl-11-methyl-dodecaonte & 38.101 & $\operatorname{tr}$ & $\operatorname{tr}$ \\
\hline 32. & Phthalic acid, isobutyl octadecylsilane & 39.916 & $\operatorname{tr}$ & $\operatorname{tr}$ \\
\hline 33. & 1,3-benzodioxole,5-[1-[2-(2-butoxyethoxy) ethoxy]butyl] & 39.946 & - & $\operatorname{tr}$ \\
\hline 34. & Neocurdione & 40.536 & - & $\operatorname{tr}$ \\
\hline 35. & Butyl lauryl phthalate & 42.082 & - & $\operatorname{tr}$ \\
\hline 36. & Methyl 11,14-octadecadienoate & 42.282 & - & $\operatorname{tr}$ \\
\hline 37. & Methyl-9-cis-11-trans-octadecadienoate & 42.302 & - & $\operatorname{tr}$ \\
\hline 38. & Ethyl lenolenate & 42.727 & - & $\operatorname{tr}$ \\
\hline 39. & Isoquinoline, 1,2,3,4-tetrahydro-1-methyl & 42.888 & $\operatorname{tr}$ & 1.279 \\
\hline 40. & 1- bromotricontane & 43.588 & - & $\operatorname{tr}$ \\
\hline 41. & $\alpha$ - guariene & 44.748 & 0.594 & - \\
\hline 42. & Fumaric acid, 2-dimethyl amino ethyl octadecyl ester & 45.063 & $\operatorname{tr}$ & 0.254 \\
\hline 43. & Trans- isolongifolene & 45.183 & 0.112 & $\operatorname{tr}$ \\
\hline 44. & 10-chlorotricyclo[4.2.1.1(2,5)] Deca-3,7-Dion-9-ol & 45.303 & 3.21 & - \\
\hline 45. & Dimethyl 1,2,5-cycloheptatriene & 45.353 & 0.092 & - \\
\hline 46. & 2-(3-isopropyl-4-methyl-pent-3-en-1-ynyl)-2-methyl-cyclobutanone & 45.503 & 0.073 & - \\
\hline 47. & 9-acetyl-s-octahydrophenanthrene & 45.618 & 0.995 & - \\
\hline 48. & Stearyl iodide & 46.644 & $\operatorname{tr}$ & 0.091 \\
\hline 49. & Isoheneicosane & 46.654 & $\operatorname{tr}$ & 0.082 \\
\hline 50 & Di-isooctyladipate & 47.184 & - & 0.091 \\
\hline 51. & Bis (2-ethylhexyl) adipate & 47.189 & - & 0.070 \\
\hline 52. & Retinene & 49.150 & 2.293 & - \\
\hline 53. & Isoaromadendrene & 50.750 & 0.795 & - \\
\hline 54. & Methyl acetoacetate & 50.955 & 0.466 & $\operatorname{tr}$ \\
\hline 55. & Trans- longipinocarveol & 51.059 & 0.754 & $\operatorname{tr}$ \\
\hline 56. & Trans- retinal & 52.896 & 0.710 & - \\
\hline
\end{tabular}

${ }^{a}$ Compounds are listed in the order of elution on BP-1 column. t, trace $(<0.05 \%)$.

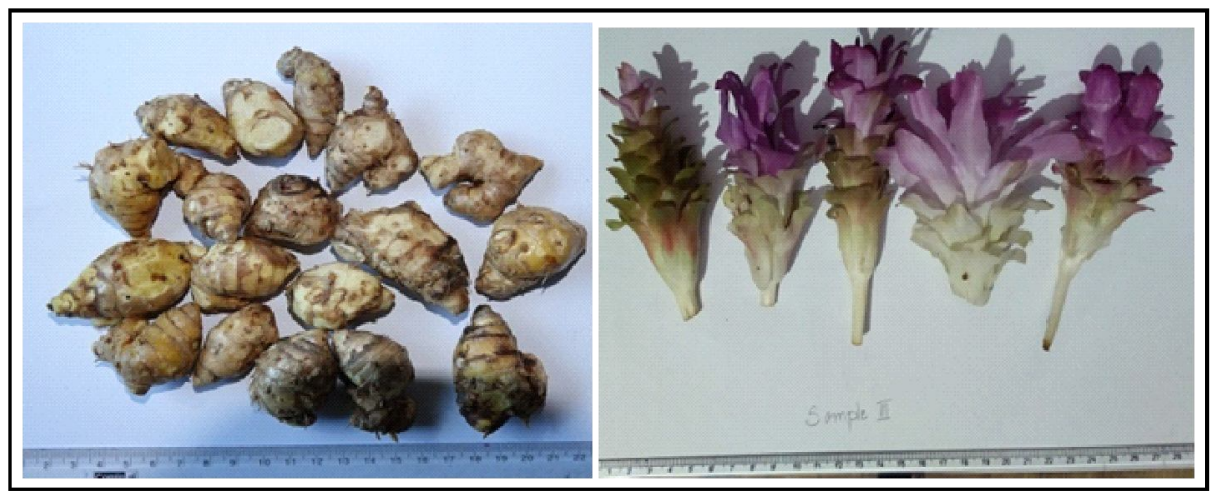

Figure 1: C. angustifolia : (a) Rhizome and ( b) Flower. 


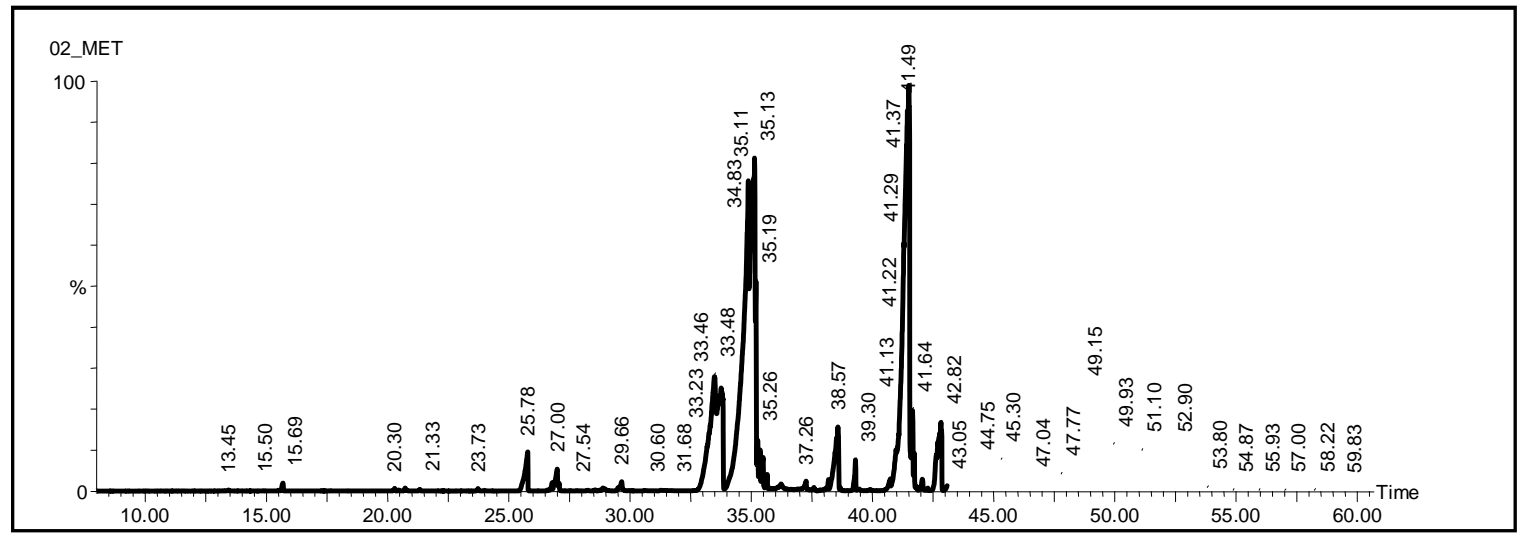

(a)

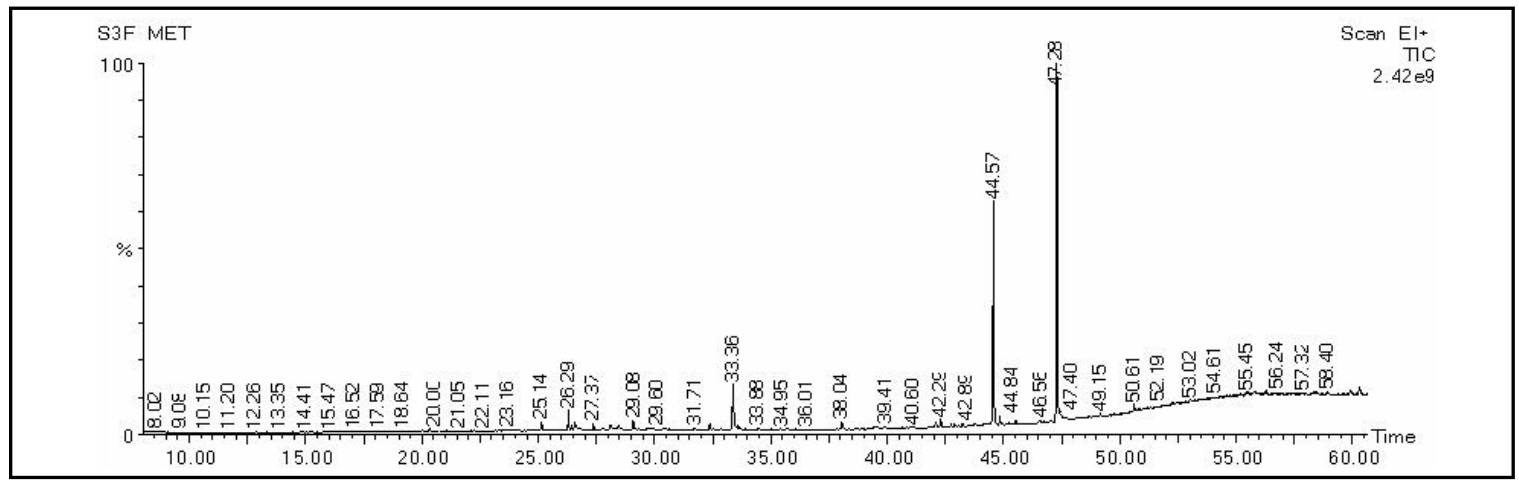

(b)

Figure 2: GC-MS chromatogram: (a) Rhizome and (b) Flower extracts of C. angustifolia.

\subsection{Flower volatile oils}

The composition of the flower volatile oil has been carried out by GC and GC-MS. The oil yield was $2.40 \%$ (v/w). Forty-two components were identified (Table 1; Figure 2, b) representing 46-61\% of the total flower oils. $\beta$-germacrene $(22.44 \%), 2,2,7,7$-tetramethyl tricycle[6.2.1.0](1,6)]undeca-4-en-3-one $(15.63 \%)$, caryophyllene oxide $(7.12 \%), \beta$-caryophyllene $(6.84 \%)$, methyl-isomyristate $(5.23 \%)$ and germacrone $(4.03 \%)$ were the major constituents in the flower oils. The percentage composition of other trace constituents in the flower oils did not show much difference, as evident from Table 1 .

\section{Discussion}

\subsection{Qualitative and quantitative report}

The essential oil of rhizome of $C$. angustifolia produced from North East India was compared to earlier reports. Rhizome oil of $C$. angustifolia showed to contain ar-curcumin, $\alpha$-pinene, $\alpha$-terpineol, camphor, zinbiberol, borneol (Banerjee et al., 1980), curzerenone (Nguyen et al., 2001), furanodienone, isofuranodienone (Nguyen $e t$ al., 2001), xanthorrhizol isomer, methyl eugenol, palmitic acid, germacron, isoborneol, curdione, 1,8-cineole (Srivastava et al., 2006; Thongkhwan et al., 2017). Young rhizome exhibited the presence of major compounds such as $\alpha$-amorphene, camphor, 2,7napthalenediol, trans-nerolidol, octadecanoic acid, butyl ester, humulen-6,7-epoxide (Nayak et al., 2014) which is not fully in support to our results. Presence of camphor, germacrene, $\beta$-elemene and $\beta$ - pinene has also been found in some Curcuma species (Zwaving and Bos, 1992; Devi et al., 2012; Chane-Ming et al., 2003). Rhizomes of C. angustifolia obtained from central and southern India was also reported to be rich in camphor, germacrene, $\alpha$-elemene and $\alpha$-pinene (Srivastava et al., 2006). The presenr report was performed in methanol extracts of $C$. angustifolia rhizome and flower which revealed the presence of major phytochemicals. This result supported with previous reported studies on methanolic extracts of Aegle marmelos (Tiwari et al., 2016). The volatile oil of flower of many important medicinal and aromatic herbs had not been exploited. The flower essential oils of Zingiber kerrii Craib were reported to contain $\alpha$-caryophyllene, $\alpha$-pinene, $\alpha$-pinene as dominant compounds (Aknerin et al., 2020) which is in partial corroborate with our report for C. angustifolia flower. Variation in qualitative and quantitative data of essential oil in medicinal and aromatic herbs is affected by various environmental factors such as temperature, rainfall, humidity, plant nutrition, genetic variation, stress during maturity and geographical location (Raut and Karuppayil, 2014; Sangwan et al., 2001; Rahimmalek et al., 2013). Genetic pattern of the plant also affect the production of essential oil (Hassiotis et al., 2014).

\subsection{Bioactiviy of methanolic extract of $C$. angustifolia}

Germacrone which is major constituent of rhizome oil showed antiinflammatory (Hossain et. al., 2015), antiandrogenic (Sephrom et. al., 2012) and antimicrobial (Kamazeri et al., 2012) activities. $\beta$ caryophyllene which is a major constituent in flower oil exhibited antitumor (Tisserand and Young, 2014), antileishmanial (Soares et 
al., 2013) and antitrypanosomal (Izumi et al., 2012) properties. These phytocompounds present in rhizome and flower extracts of C. angustifolia has potent bioactivity and is useful for effective herbal formulations and preparation of drugs in pharmaceutical companies.

\section{Conclusion}

The chemical constituents in volatile oils distilled from rhizome and flower of $C$. angustifolia was investigated using GC-MS technique. The composition and quantitative data of the flower volatile oil of $C$. angustifolia are reported for the first time. These constituents could be used for the utilization of development of traditional medicines and investigation in the field of antioxidant and antimicrobial assay needs to be conducted. The present investigation has significantly contributed to the existing knowledge of volatile oil composition of methnolic extract of rhizome and flower of $C$. angustifolia found in North East India. The identified compounds can be utilized as pharmacognostical tools. The current study suggests that methanolic extract of this plant parts is a potent therapeutic agent. It paves the way for the development of several treatment regimens using the extracts and further research is necessary to identify and purify the active compounds responsible for therapeutic activities.

\section{Author contributions}

All the authors contributed to the concept and design of the experiments. N. Shilpia Devi executed the labwork while N. Sandhyarani Devi contributed in statistical analysis, interpretation of data and manuscript preparation. R.K. Imotomba Singh helped in conceptualization and support.

\section{Conflict of interest}

The authors declare no conflicts of interest relevant to this article.

\section{References}

Aknarin, P.; Surat, L.; Emilie, L.;Wim, V.G. and Wisanu, M. (2020). Chemica composition of essential oils from different parts of Zingiber kerrii Craib and their antibacterial, antioxidant, and tyrosinase inhibitory activities. Biomolecules, 10:1-13.

Alam, A.; Kanchan and Iwuala, E. (2019). Contemporary medicinal uses of ethnomedicinally important plant: Arjuna (Terminalia arjuna (Roxb.) Wight and Arn.). Ann. Phytomed., 8(1):63-69.

Atlas, R.M.; Parks, L.C. and Brown, A.E. (1995). Laboratory manual of experimental microbiology. Mosby-Year Book Inc., St. Louis, Missouri.

Banerjee, A., Kaul, V.K. and Nigam, S.S. (1980). Riv. Ital. Essenze. Perfumi. Piaute Off., Aromat., Syndets Saponi Cosmet. Aerosols, 62 (2):7576.

Chane-Ming, J.; Vera, R. and Chalchat, J.C. (2003). Chemical composition of the essential oil from rhizomes, leaves and flowers of Zingiber zerumbet Smith from Reunion Island. J. Essential Oil Res., 15:202205

Devi, L.R.,;Rana, V.S.; Devi, S.I.; Verdeguer, M. and Amparo Blázquez, M. (2012). Chemical composition and antimicrobial activity of the essential oil of Curcuma leucorhiza Roxb. J. Essential Oil Res., 24: 533-538.

Devi, N.B.; Singh, P.K. and Das, A.K. (2014). Ethnomedicinal Utilization of Zingiberaceae in the Valley Districts of Manipur. IOSR Journal of Environmental Science. Toxicol. Food Technol, 8 (2):21-23.
Guether, E. (1972). The production of essential oils. In: Robert E (ed) The essential oils, vol I. Krieger, New York: 361-391.

Hassiotis, C.N.; Ntana, F.; Lazari, D.M.; Poulios, S. and Vlachonasios, K.E. (2014). Environmental and developmental factors affect essential oil production and quality of Lavandula angustifolia during flowering period. Ind. Crops Prod., 62:359-366.

Hossain, C.F.; Al-Amin, M.; Sayem, A.S.M.; Siragee, I.H.; Tunan, A.M.; Hassan, F.; Kabir, M.M. and Sultana, G.N.N. (2015). Antinociceptive principle from Curcuma aeruginosa BMC Complement. Altern. Med., 15:191.

Izumi, E.; Ueda-Nakamura, T.; Veiga, V.F.; Pinto, A.C. and Nakamura, C.V. (2012), Terpenes from Copaifera demonstrated in vitro antiparasitic and synergic activity. J. Med. Chem., 55:2994-3001.

Jain, S.K. (1995). Ethnobotanical diversity in Zngibers of India. Ethnobot., 7:83-88.

Kamazeri, T.S.A.T.; Samah, O.A.; Taher, M.; Susanti, D. and Qaralleh, H. (2012) Antimicrobial activity and essential oils of Curcuma aeruginosa, Curcuma mangga, and Zingiber cassumunar from Malaysia. Asian Pac. J. Trop. Med., 5:202-209.

Lee, S.; Son, D.; Ryu, J.; Lee, Y.S.; Jung, S.H.; Kang, J.; Lee, S.Y.; Kim, H.S. and Shin, S.H. (2004). Antioxidant activities of Acanthopanax senticosus stems and their lignin components. Arch. Pharm. Res., 27:106-110.

Manoharachary, C. and Nagaraju, D. (2016). Medicinal plants for human health and welfare. Ann. Phytomed., 5(1):24-34.

Maciel, N. and Criley, R.A. (2003). Morphology, growth and flowering behavior of Curcuma zedoaria. Acta Hort. (ISHS) 624:111-116.

Nayak, S.; Jena, A.K.; Mittal, D.K, and Joshi, D. (2014). GC-MS analysis of phytoconstituents of some wild zingiberaceae plants methanlic rhizhome extract. Res. Plant Sci., 2(1): 1-5.

Nguyen, T.B.T.; Trinch, D.C.; Do, D.R. and Nguyen, X.D. (2011). Veitnam Hoa Hoc Va Cong Nghiep Hao Chat, 5:11-14 [CAN 136: 180650].

Nguyen, T.B.T.; Trinch, D.C.; Do, D.R. and Nguyen, X.D. (2011). Veitnam Hoa Hoc Va Cong Nghiep Hao Chat, 4:28-32 [CAN 136: 2944].

Padal, S.B. and Sandhyasri, B. (2013). Ethnomedocinal investigation of medicinal plants of Sovva Panchayat, Dumbriguda Mandalam, Vishakapatnam District, Andhra Pradesh. Int. J. Eng. Sci., 2(5): 556-61.

Rahimmalek, M.; Mirzakhani, M. and Pirbalouti, A.G. (2013). Essential oil variation among 21 wild myrtle (Myrtus communis L.) populations from different geographical regions in Iran. Ind. Crops Prod., 51:328333 .

Raut, J.S. and Karuppayil, S.M. (2014). A status review on the medicinal properties of essential oils. Ind. Crops Prod., 62:250-264.

Ray, S.; Sheikh, M. and Mishra, S. (2011). Ethnomedicinal plants used bt tribals of East Nimar region, Madhya Pradesh. Indian J. Tradit. Knowl., 10(2): 367-371.

Sangwan, N.S.; Farooqi, A.H.A.; Shabih, F. and Sangwan, R.S. (2001). Regulation of essential oil production in plants. Plant Growth Regul., 34: 321.20 .

Sharma, A. (2012). Traditional processing of Shotti (Curcuma augustifolia Roxb.): A rhizome based ethnic weaning food. Indian J. Tradit. Knowl., 11(1):154-155.

Soares, D.C.; Portella, N.A.; Ramos, M.F.D.S.; Siani,A.C. and Saraiva, E.M. (2013). trans-Caryophyllene: An effective antileishmanial compound found in commercial copaiba oil (Copaifera spp.). Evid.-Based Complement. Altern. Med. pp:1-13.

Srivastava, A.K.; Srivastava, S.K. and Syamsundar, K.V. (2006). Volatile composition of Curcuma angustifolia Roxb. rhizome from central and southern India. Flavour Frag. J., 21:423-426. 
Sudipta, J.; Asit R.; Anwesha, B.; Ambika, S.; Noohi, N.; Suprava, S.; Basudeva, K.; Jeetendranath, P.; Pradip, C.P. and Sanghamitra, N. (2017). Chemical composition and antioxidant activity of essential oil from leaves and rhizomes of Curcuma angustifolia Roxb. Nat. Prod. Res., 31(18) 2188-2191.

Suphrom, N.; Pumthong, G.; Khorana, N.; Waranuch, N.; Limpeanchob, N. and Ingkaninan, K. (2012). Anti-androgenic effect of sesquiterpenoids isolated from the rhizomes of Curcuma aeruginosa Roxb. Fitoterapia, 83:864-871.

Thongkhwan, P.; Chaibunga, T.; Kwanboonjan, H. and Theanphong, O. (2017) Essential constituents of the fresh root and rhizome of Curcuma angustifolia Roxb. from Thailand. Bul.1 Heal. Sci. Technol., 15:5253.
Tisserand, R. and Young, R. (2014). Essential Oil Safety, 2nd ed.; Elsevier: Edinburgh, UK.

Tiwari, B.; Abidi, A.B.; Rizvi, S.I. and Pandey, K.B. (2016). Phytochemical screening and evaluation of antioxidant potentials of some Indian medicinal plants and their composite extract. Ann. Phytomed., 5(1): 99-103.

Tushar, B. S.; Sarma, G.C. and Rangan, L. (2010). Ethnomedicinal uses of Zingiberaceous plants of Northeast India. J. Ethnopharmacol., 132(1): 286-296.

Zwaving, J.H. and Bos, R. (1992). Analysis of the essential oils of five Curcuma species. Flavour Frag. J., 7:19-22. 